\title{
Application of Distress Thermometer in Patients with Prostatic Cancer and Prostatitis
}

\author{
Xin Wang, Chang-Xuan Chen*, Qian Wang, Lei Wang \\ Department of Urology, Tengzhou Central People's Hospital, Tengzhou, China \\ Email: *wangxin378@126.com
}

How to cite this paper: Wang, X., Chen, C.-X., Wang, Q. and Wang, L. (2017) Application of Distress Thermometer in Patients with Prostatic Cancer and Prostatitis. Open Journal of Urology, 7, 227-234. https://doi.org/10.4236/oju.2017.712027

Received: September 10, 2016 Accepted: November 28, 2017

Published: December 1, 2017

Copyright $\odot 2017$ by authors and Scientific Research Publishing Inc. This work is licensed under the Creative Commons Attribution International License (CC BY 4.0).

http://creativecommons.org/licenses/by/4.0/

\begin{abstract}
Objective: To discuss the application of distress thermometer (DT) on psychological pain in primary hospital patients with prostatic cancer (Pca) and prostatitis; and to analyze the present status and related factors of psychological pain in these patients. Methods: Questionnaire survey of DT and related problem lists were carried out in 168 patients with Pca and 226 patients with prostatitis. The data were input to EXCEL and analyzed with SPSS 18.0. The statistical description was used to analyze the graded of psychological pain. Square test and Logistic regression were used to analyze influence factors of significant psychological distress. Pearson correlation analysis was used to assess the correlation between psychological distress and related problems. Results: Psychological pain score of Pca patients and prostatitis patients were $3.42 \pm 1.86$ and $3.02 \pm 1.75$, respectively. Moderate to severe degree of pain accounted for $69.6 \%$ in Pca patients, compared to $49.1 \%$ in prostatitis patients. In Pca and prostatitis patients, marital status, age, educational backgrounds and income were associated. Physical and emotional problems were the top two items having the highest score. Psychological distress score was positively correlated with physical problems, emotional problems, practical problems and communication problems in both Pcar and prostatitis patients. Conclusion: The Distress Thermometer can be used to assess the severity and explore the causes of psychological distress in Pca patients and prostatitis patients. Our study could help detecting the degree and reason of psychological distress, and provide evidence for the possibility of future personalized intervention to treat medical mental problems in primary hospital.
\end{abstract}

\section{Keywords}

Prostatic Cancer, Prostatitis, Psychological Distress, Psychological Distress Thermometer Scale 


\section{Introduction}

Disease causes physical distress as well as psychological distress at the same time, especially in cancer patients [1]. Psychological distress, which is the unpleasant experiences including frustration, sadness, fear, anxiety, depression, social isolation and spiritual crisis, can be caused by many factors [2]. These will affect the treatment effectiveness. Severe psychological distress can affect the prognosis of the disease. But the psychological distress is often overlooked or underestimated by clinicians, and lack of access to treatment, and delays in diagnosis and treatment of the disease [3]. Therefore, United States national comprehensive cancer network (NCCN) recommends a rapid and effective psychological distress screening instrument-distress thermometer, DT [4]. It is widely used in Clinical Oncology, assessing the situation of psychological distress in cancer patients timely and, if necessary, applying psychological intervention [5]. Currently, distress thermometers are often used in psychological distress in patients with cancer including prostate cancer [6] [7] [8], but have not yet been applied to benign diseases. Prostatitis is a common disease in adult males, accounting to $8 \%-25 \%$ of patients in the Urology Clinic [9]. Type III prostatitis is a disease lack of evidence of organic pathology. Prostatitis is often accompanied by depression, anxiety and somatoform disorders (hypochondria disorder), and psychological factors is now highlighted [10]. Therefore, psychological distress in patients with prostatitis is quite common, and severe psychological distress affects recovery of the disease, distress thermometer should be valuable in treatment of prostatitis patients.

\section{Methods and Patients}

The patients in clinic or wards of urology of our hospital were questionnaired. Recruit criteria includes: 1) Diagnosis of prostatitis by symptoms and prostate fluid or diagnosis of prostate cancer by pathology; 2) Patients answered the questionnaire; 3) Patients filled the informed consent. Four hundred and twenty questionnaires were collected, where 394 were effective. One hundred and sixty eight patients were prostate cancer and 238 were prostatitis, including 56 of type I, 72 of type II, 98 of type III, 12 of type IV.

\subsection{Research Tool}

Distress thermometer is designed by Dr. Roth for self evaluation of single psychological distress. The major part of 11 score evaluation mimics the thermometer from 0 (no distress) to 10 (extreme distress). Patients were instructed to record their average distress scores of the past week as mild distress of 1 - 3, moderate distress of $4-6$ and severe distress of $7-9$. NCCN defines 4 points as a standard for psychologist evaluation and treatment [11] [12].

\subsection{Methods}

Urologists trained by psychologists and epidemiologists provide the question- 
naires and informed consents to patients. All questionnaires and informed consents were finished by patients themselves. For the patients cannot read the questionnaires and forms, family members help them to fill the forms.

\subsection{Statistics}

Data were analyzed by SPSS18.0 software. Psychological distress was expressed as mean scores \pm standard deviation $( \pm s)$, using Chi square test and Logistic regression analysis on influencing factors of psychological distress, using Pearson correlation analysis on correlation between psychological distress scores and related issues.

\section{Results}

1) Psychological distress of prostate cancer patients and prostatitis patients (Table 1): average psychological distress score of prostate cancer patients was $3.42 \pm 1.86$, mainly were moderate distress, accounting to $48.8 \%$ of total patients. Significant psychological distress (scores equal or higher than 4) accounted to $69.6 \%$ of total patients. Average psychological distress score of prostatitis patients was $3.02 \pm 1.75$, mainly were mild distress (42.5\%), $49.1 \%$ of patients had significant distress.

2) Analysis of factors influencing on psychological distress of prostate cancer and prostatitis: Significant psychological distress of prostate cancer patients were significantly different with patients without significant psychological distress in marriage status, ages, education and income $(\mathrm{p}<0.05$, Table 2$)$. So were

Table 1. Distribution of psychological distress of prostate cancer and prostatitis patients [cases, (\%)].

\begin{tabular}{ccccccc}
\hline Disease & Cases number & No distress & Mild distress & $\begin{array}{c}\text { Moderate } \\
\text { distress }\end{array}$ & $\begin{array}{c}\text { Severe } \\
\text { distress }\end{array}$ & $\begin{array}{c}\text { Extreme } \\
\text { distress }\end{array}$ \\
\hline $\begin{array}{c}\text { Prostate } \\
\text { cancer }\end{array}$ & 168 & $9(5.4)$ & $42(25.0)$ & $82(48.8)$ & $25(14.9)$ & $10(5.9)$ \\
Prostatitis & 226 & $19(8.4)$ & $9642.5)$ & $68(30.1)$ & $26(11.5)$ & $17(7.5)$ \\
\hline
\end{tabular}

Table 2. Single factor analysis of psychological distress in prostate cancer patients.

\begin{tabular}{|c|c|c|c|c|c|c|}
\hline & & Cases & $\begin{array}{l}\text { Insignificant } \\
\text { stress }\end{array}$ & $\begin{array}{l}\text { Significant } \\
\text { stress }\end{array}$ & $\mathrm{X}^{2}$ & $\mathrm{P}$ \\
\hline & Married & 126 & 84 & 42 & & \\
\hline Marriage & $\begin{array}{c}\text { Unmarried, divorced } \\
\text { or willowed }\end{array}$ & 42 & 11 & 31 & 21.003 & 0.000 \\
\hline Age & $\begin{array}{l}<60 \\
>60\end{array}$ & $\begin{array}{r}32 \\
136\end{array}$ & $\begin{array}{l}10 \\
96\end{array}$ & $\begin{array}{l}22 \\
40\end{array}$ & 17.216 & 0.000 \\
\hline Education & $\begin{array}{l}\text { Above high school } \\
\text { Under high school }\end{array}$ & $\begin{array}{r}22 \\
146\end{array}$ & $\begin{array}{l}18 \\
68\end{array}$ & $\begin{array}{c}4 \\
78\end{array}$ & 9.504 & 0.002 \\
\hline Month income & $\begin{array}{l}\geq 2000 \mathrm{RMB} \\
<2000 \mathrm{RMB}\end{array}$ & $\begin{array}{c}62 \\
106\end{array}$ & $\begin{array}{l}32 \\
34\end{array}$ & $\begin{array}{l}30 \\
72\end{array}$ & 6.26 & 0.010 \\
\hline
\end{tabular}


prostatitis patients $(\mathrm{p}<0.05$, Table 3$)$.

3) Multi-factor analysis of prostate cancer patients and prostatitis patients (Table 4): Marriage, age, education and income are protective to prostate cancer patients, OD were $0.196,0.238,0.064$ and 0.062 respectively, patients in marriage, older age, more education and higher income were with lower incidence of psychological distress. For prostatitis patients, marriage, age are risks, income and education are protective, OR are 2.640, 2.590. 0.066 and 0.082, meaning, prostate patients in marriage and with older age had higher risk of psychological distress, while more education and higher income will reduce the risk.

4) Relationship between psychological distress related problem scores and psychological distress scores (Table 5): For all patients, psychological distress related problem scores from high to low were: health, emotion, trifles and communications. Psychological stress in both prostate cancer patients and prostatitis patients were positively related with the total and each score of the four problems (for prostate cancer patients, $\mathrm{r}=0.928,0.917,0.825,0.636$ respectively, $\mathrm{p}<0.05$, for prostatitis, $\mathrm{r}=0.931,0.855,0.796,0.654,0.497$ respectively, $\mathrm{p}<0.05$ ).

Table 3. Single factor analysis of psychological distress in prostatitis.

\begin{tabular}{|c|c|c|c|c|c|c|}
\hline & & Cases & $\begin{array}{l}\text { Insignificant } \\
\text { stress }\end{array}$ & $\begin{array}{c}\text { Significant } \\
\text { stress }\end{array}$ & $\mathrm{X}^{2}$ & $\mathrm{P}$ \\
\hline & Married & 178 & 43 & 135 & \multirow[b]{2}{*}{16.052} & \multirow[b]{2}{*}{0.000} \\
\hline Marriage & $\begin{array}{c}\text { Unmarried, divorced } \\
\text { or willowed }\end{array}$ & 48 & 26 & 22 & & \\
\hline Age & $\begin{array}{l}<30 \\
>30\end{array}$ & $\begin{array}{r}62 \\
164\end{array}$ & $\begin{array}{l}37 \\
56\end{array}$ & $\begin{array}{l}25 \\
88\end{array}$ & 7.563 & 0.006 \\
\hline Education & $\begin{array}{l}\text { Above high school } \\
\text { Under high school }\end{array}$ & $\begin{array}{l}82 \\
144\end{array}$ & $\begin{array}{l}56 \\
57\end{array}$ & $\begin{array}{l}26 \\
87\end{array}$ & 17.226 & 0.000 \\
\hline $\begin{array}{l}\text { Month in- } \\
\text { come }\end{array}$ & $\begin{array}{l}\geq 2000 \mathrm{RMB} \\
<2000 \mathrm{RMB}\end{array}$ & $\begin{array}{l}186 \\
40\end{array}$ & 104 & $\begin{array}{l}82 \\
26\end{array}$ & 5.771 & 0.016 \\
\hline
\end{tabular}

Table 4. Multi factor analysis of psychological distress in prostate cancer and prostatitis.

\begin{tabular}{cccccccc}
\hline Disease & variable & B & SE & Wald & P & OR & OR95\%CI \\
\hline & Marriage & -1.469 & 0.459 & 10.238 & 0.001 & 0.196 & $0.076-0.592$ \\
$\begin{array}{c}\text { Prostate } \\
\text { cancer }\end{array}$ & Age & -1.419 & 0.480 & 9.029 & 0.001 & 0.238 & $0.089-0.612$ \\
& Education & -2.755 & 0.949 & 8.436 & 0.004 & 0.064 & $0.010-0.408$ \\
& Month income & -2.783 & 1.109 & 6.297 & 0.012 & 0.062 & $0.007-0.544$ \\
& Marriage & 0.967 & 0.442 & 4.761 & 0.030 & 2.640 & $1.101-6.300$ \\
\multirow{2}{*}{ Prostatitis } & Age & 0.970 & 0.440 & 4.698 & 0.020 & 2.590 & $1.099-6.412$ \\
& Education & 2.699 & 0.460 & 37.669 & 0.001 & 0.058 & $0.031-0.162$ \\
& & & & & & & \\
& Month income & 2.489 & 0.512 & 38.122 & 0.020 & 0.072 & $0.045-0.467$
\end{tabular}


Table 5. Evaluation of psychological stress in prostate cancer and prostatitis $\left(\begin{array}{ll}\bar{x} & \pm s\end{array}\right)$.

\begin{tabular}{ccccccc}
\hline Disease & Trifle & communication & Emotion & Health & Total scores & $\begin{array}{c}\text { Psychological } \\
\text { stress scores }\end{array}$ \\
\hline $\begin{array}{c}\text { Prostate } \\
\text { cancer }\end{array}$ & $2.24 \pm 1.96$ & $0.46 \pm 0.89$ & $4.21 \pm 3.02$ & $4.76 \pm 4.82$ & $11.67 \pm 2.25$ & $3.42 \pm 1.86$ \\
Prostatitis & $1.89 \pm 2.93$ & $0.51 \pm 1.42$ & $4.28 \pm 4.76$ & $4.56 \pm 3.01$ & $11.07 \pm 10.86$ & $3.02 \pm 1.75$ \\
\hline
\end{tabular}

\section{Discussion}

Currently, a lot of research applying DT to screening for psychological distress in cancer patients, set the cut-off point for 4 points better sensitivity, specificity, and the largest area under the curve [13]. Score $\geq 4$ points is defined as significant psychological distress where professional psychological intervention is needed. Our results found $63.7 \%$ of prostate cancer patients had mild to severe distress, lower than $74.43 \%$ of Yan Li's report [12] but higher than Zhang Yening's $24.2 \%$ [11] and $35.1 \%$ of Zabora's [14] and $37.8 \%$ of Carlson [15]. Potential reasons are the different tumor category, sample volume, filter tool, and social culture. Chinese tradition refuses to recognize psychological problems. Especially cancer patients didn't want to choose "psychological disease" of diagnosis with cancer at the same time, this "disease shame sense" makes many patients select low points, to hide real pain sense. Different to patients with prostate cancer, mainly to mild pain in prostatitis patients, accounting for $42.5 \%$, and moderate psychological distress and above accounted for $49.1 \%$. Although prostatitis is far less life-threatening than prostate cancer, the same psychological burden on the patients. But it should not be ignored, half of patients with prostatitis having significant psychological distress due to urinary tract symptoms, pain and sexual dysfunction, resulting in patients' life, work, communication, emotional, psychological, and severe psychological burden and impact the outcome of the disease. Therefore, psychological pain thermometer not only can be applied to patients with prostate cancer, detect the significant psychological distress patient, early intervention, and some patients with prostatitis is also essential.

Further analysis found single, divorced or widowed prostate cancer patients, and patients younger than 60 are more likely to have a significant psychological distress. Unmarried, divorced or widowed patients were lack of family support, psychological soothing and care from family, with this psychological loneliness, helplessness increases their suffering. Patients under 60 years, enduring pressure from work, life, and family, have psychological distress more severe than patients older than 60 years [16]. In contrast to patients with prostate cancer, married (not widowed), older than 30-year prostatitis patients are more vulnerable to significant psychological distress. Those patients have more social psychological pressure. This population is sexually active, with long sexual history and often accompanied by sexual dysfunction, caused a great deal of stress. Under the influence of Chinese traditional ideology, the patient feels ashamed to reveal the 
condition, and they hurt a person's self-esteem and confidence, that also led to tension between couples. Those factors can easily lead to psychological distress.

According to this study, prostate cancer and prostatitis patients 'psychological distress was negatively correlated with education and income. Educated patients have a breadth of knowledge, rich in strong health consciousness, the learning channel, can be rationally recognize the disease through a variety of media, as informed as possible of the disease easy to correct, and at ease with the face of disease, with the treatment effect is better. Low education level, due to lack of health knowledge, tend to believe in the quack, street ads false propaganda in the informal media, seriously affect the diagnosis and treatment of Prostatitis, thereby affecting their mental changes, causing suspicion, speculation, and even fear, leading to severe psychological pain. Progression of prostate cancer is complicated, and there are numerous prostatitis patients [9], the economy better able to withstand disease long-term treatment in patients with enormous economic pressures, and patients with unfavourable economic conditions often worried about costs too much or have no money for treatment, and psychological disorders such as anxiety, depression, could easily lead to serious psychological distress [17].

This study found that factors influencing psychological distress evaluation scores in prostate cancer and prostatitis patients from high to low are health, emotion, trifles and communication issues. In patients with prostate cancer, emotional problems and communication were positively related. Patients with health and emotional problems that best reflect the degree of psychological distress, medical workers should pay close attention to patients with health problems and emotional problems. Health problems in patients with prostate cancer are mainly changes in urination, pain, and urinary tract symptoms. In patients with bone metastases is related to health problems mainly in urine of patients with prostate changes, pain, sex, sex in the patient with sexual dysfunction problems. Therefore, somatic symptoms of patients with clinical ease and control can be effective in reducing pain. Emotional problems are also higher, mainly for patients with prostate cancer and prostatitis worry, depression and stress, sleep, loss of interest in daily activities in patients with prostatitis also has many manifestations. Therefore, patients should be active in psychological counseling, if necessary, referral to a professional psychiatrist for treatment. Practical problems, both major economic problems, it is not only the common problems occurred in the treatment of cancer patients. Chronic prostatitis and chronic diseases, such as the problems faced by patients, but with my health insurance universal, perfect, and the strengthening of grass-roots hospitals, this improvement in sight. Finally, communication problems, both largely communication problems, ashamed of his condition told family or friends and relatives. The worst is that many patients is more difficult to communicate with the medical staff, mainly taking into account that the current health care environment and the limited communication between medical, therefore, actively communicating with 
patients and their families, medical personnel exchanges.

\section{Conclusion}

Above all, psychological distress thermometer as a mental health screening tool, intuitive, simple, and involving a wide range of relevant factors, can help clinicians quickly assess patients and causes of psychological distress, clinical psychological intervention and treatment so as to provide a good basis. It applies not only to patients with cancers such as prostate cancer, and for prostatitis patients with significant mental problems as well. However, this is investigated in elementary health providing hospital studied, future work should be improved in depth, so that it can be very well for clinical psychological intervention and treatment to provide a good foundation basis.

\section{References}

[1] Akizuki, N., Akechi, T., Nakanishi, T., et al. (2003) Development of a Brief Screening Interview for Adjustment Disorders and Major Depression in Patients with Cancer. Cancer, 97, 2605-2613. https://doi.org/10.1002/cncr.11358

[2] Holland, J.C., Andersen, B., Breitbart, W.S., et al. (2010) NCCN Clinical Practice Guidelines in Oncology, Distress Management. Journal of the National Comprehensive Cancer Network, 8, 448-485. https://doi.org/10.6004/jnccn.2010.0034

[3] Jacobsen, P.B. and Ransom, S. (2007) Implementation of NCCN Distress Management Guidelines by Member Institutions. Journal of the National Comprehensive Cancer Network, 5, 99-103. https://doi.org/10.6004/jnccn.2007.0010

[4] Snowden, A., White, C.A., Christie, Z., et al. (2011) The Clinical Utility of the Distress Thermometer: A Review. British Journal of Nursing, 20, 220-227. https://doi.org/10.12968/bjon.2011.20.4.220

[5] Holland, J.C., Andersen, B., William, S., et al. (2013) Distress Management. Journal of the National Comprehensive Cancer Network, 11, 190-209.

https://doi.org/10.6004/jnccn.2013.0027

[6] Goebel, S. and Mehdorn, H.M. (2011) Measurement of Psychological Distress in Patients with Intracranial Tumours: The NCCN Distress Thermometer. Journal of Neuro-Oncology, 104, 357-364. https://doi.org/10.1007/s11060-010-0501-5

[7] Lynch, J., Goodhart, F., Saunders, Y., et al. (2011) Screening for Psychological Distress in Patients with Lung Cancer: Results of a Clinical Audit Evaluating the Use of the Patient Distress Thermometer. Support Care Cancer, 19, 193-202. https://doi.org/10.1007/s00520-009-0799-8

[8] Tang, L.L., Zhang, Y.N., Pang, Y., et al. (2011) Validation and Reliability of Distress Thermometer in Chinese Cancer Patients. Chinese Journal of Cancer Research, 23, 54-58. https://doi.org/10.1007/s11670-011-0054-y

[9] Krieger, J.N., Riley, D.E., Cheah, P.Y., et al. (2003) Epidemiology of Prostatitis: New Evidence for a World-Wide Problem. World Journal of Urology, 2, 70-74.

[10] Wu, L., Liang, C., Tang, Z., et al. (2006) Analysis of Psychological Stress in 1426 Chronic Prostatitis Patients. Chinese Journal of Urology, 27, 512-515.

[11] Zhang, Y., Zhang, H., Song, L., et al. (2010) Application of the NCCN Distress Thermometer in Chinese Cancer Patients. Chinese Mental Health Journal, 24, 897-902. 
[12] Yan, L., Xu, Z., Li, X., et al. (2012) Study of Application of Distress Thermometer in Malignant Cancer Patients. Chinese Journal of Nursing, 27, 73-75.

[13] Mertz, B.G., Bistrup, P.E., Johansen, C., et al. (2011) Psychological Distress among Women with Newly Diagnosed Breast Cancer. European Journal of Oncology Nursing, 16, 439-443. https://doi.org/10.1016/j.ejon.2011.10.001

[14] Zabora, J., Brintzenhofeszoc, K., Curbow, B., et al. (2001) The Prevalence of Psychological Distress by Cancer Site. Psychooncology, 10, 19-28. https://doi.org/10.1002/1099-1611(200101/02)10:1<19::AID-PON501>3.0.CO;2-6

[15] Carlson, L.E., Angen, M., Cullum, J., et al. (2004) High Levels of Untreated Distress and Fatigue in Cancer Patients. British Journal of Cancer, 90, 2297-2304. https://doi.org/10.1038/sj.bjc.6601887

[16] Krok, J.L., Baker, T.A., McMillan, S.C., et al. (2013) Age Differences in the Presence of Pain and Psychological Distress in Younger and Older Cancer Patients. Journal Of Hospice \& Palliative Nursing, 15, 107-113. https://doi.org/10.1097/NJH.0b013e31826bfb63

[17] Caron, J. and Liu, A. (2011) Factors Associated with Psychological Distress in the Canadian Population: A Comparison of Low-Income and Non Low-Income Sub-Groups. Community Mental Health Journal, 47, 318-330.

https://doi.org/10.1007/s10597-010-9306-4 